\title{
Pengembangan Sistem Manajemen Baterai Pada PLTS Menggunakan On-Off Grid Tie Inverter
}

\author{
Sapto Prayogo \\ Jurusan Teknik Konversi Energi Politeknik Negeri Bandung \\ E-mail: saptoprajogo@gmail.com
}

\begin{abstract}
Abstrak
Permasalahan pada Pembangkit Listrik Tenaga Surya (PLTS) yang menggunakan inverter jenis on/off grid tie inverter adalah tidak dilengkapi dengan mekanisme kontrol penyimpanan daya ke baterai. Dimana pada saat bekerja sebagai on grid inverter maka baterai seharusnya terlepas dari inverter hal ini ditujukan untuk menghindari baterai terjadi over discharge karena daya keluaran pada inverter saat on grid akan bekerja maksimum dengan adanya MPPT. Sementara pada saat off grid, baterai harus terhubung dengan inverter untuk menstabilkan daya keluaran inverter karena adanya fluktuasi radiasi matahari dan beban AC. Pada penelitian ini dikembangkan sistem manajemen baterai untuk mengatur mekanisme pengisian dan pembebanan baterai pada inverter jenis on/off grid. Sistem manajemen baterai akan mengatur mekanisme pengisian baterai pada saat bekerja sebagai on grid inverter dan mengatur interkoneksi ke inverter pada saat bekerja sebagai off grid inverter, khususnya untuk mengantisipasi kondisi over charge dan over discharge. Hasil pengujian menunjukkan efesiensi BCU sebesar 95,1\% dan efesiensi inverter sebesar 94,8\%. Waktu transisi yang diperlukan untuk berpindah dari kondisi off grid ke kondisi on grid selama 41,4 detik. Perpindahan interkoneksi baterai dengan rangkaian inverter ke rangkaian pengisian baterai tidak mengganggu kinerja rangkaian PLTS on/off grid.
\end{abstract}

Keywords: on grid, off grid, inverter, MPPT, baterai

\section{Pendahuluan}

Pada pembangkit listrik tenaga surya diperlukan perangkat inverter yang digunakan untuk merubah daya listrik DC dari panel surya menjadi daya listrik AC untuk mensuplai beban-beban yang membutuhkan sumber listrik AC. Ada beberapa tipe inverter yang digunakan pada pembangkit listrik tenaga surya (PLTS) sesuai dengan konfigurasi PLTS. ada dua jenis konfigurasi PLTS yang umum digunakan yaitu PLTS tidak terhubung jaringan dan PLTS terhubung jaringan.

Pada PLTS dengan konfigurasi tidak terhubung jaringan/mandiri/isolated maka digunakan stand alone inverter (off grid inverter). Inverter jenis off grid dapat bekerja secara mandiri akan tetapi tidak dapat dihubungkan dengan jaringan dan daya listrik keluaran sesuai dengan besaran daya yang dibutuhkan oleh beban $\mathrm{AC}[1]$. Untuk stabilisasi daya keluaran karena perubahan pada sumber energi listrik yang berasal dari matahari dan perubahan pada beban maka pada PLTS mandiri dilengkapi dengan baterai. Penggunaan baterai ditujukan untuk menyimpan kelebihan daya ketika beban rendah dan dapat ikut mensuplai daya bersama daya keluaran panel surya ketika kebutuhan daya beban tinggi.

Pada PLTS terhubung dengan jaringan PLN digunakan inverter jenis on grid inverter. Daya keluaran inverter dapat disalurkan ke jaringan, karena memiliki kemampuan sinkronisasi. Daya keluaran inverter tidak bergantung pada besarnya beban yang terhubung dengan inverter akan tetapi sebanding dengan besarnya daya yang dihasilkan oleh panel surya saat itu[2]. Agar dapat menghasilkan daya maksimal yang sebanding dengan potensi radiasi saat itu maka on grid inverter selalu dilengkapi dengan modul MPPT ( maximum power point tracking). Inverter jenis ini tidak membutuhkan baterai, untuk stabilisasi operasi karena fluktuasi daya pada sumber matahari dan beban di kompensasi oleh daya dari dan ke jaringan PLN. Inverter on grid baru dapat bekerja menghasilkan daya listrik ketika terhubung dengan jaringan, jika inverter jenis ini terputus dengan jaringan, karena pemadaman, maka tidak ada daya listrik yang dihasilkan meskipun saat itu matahari bersinar terik, jadi tidak dapat difungsikan sebagai daya cadangan.

Saat ini ada inverter jenis on/off grid tie inverter dimana inverter jenis ini dapat bekerja sebagai inverter mandiri 
(off grid) maupun inverter on grid artinya inverter ini merupakan gabungan dari dua jenis inverter diatas[3]. Artinya saat ada daya listrik dari PLN maka inverter ini akan bekerja sebagai on grid inverter, daya yang dihasilkan akan mengurangi konsumsi listrik yang disuplai dari PLN. Pada saat terjadi pemadaman maka inverter bekerja sebagai off grid inverter dengan menyalurkan daya dari solar panel dan baterai yang digunakan untuk menyimpan energi.

Permasalahannya pada inverter jenis ini tidak dilengkapi dengan mekanisme kontrol penyimpanan daya ke baterai. Dimana pada saat bekerja sebagai on grid inverter maka baterai seharusnya terlepas dari inverter hal ini ditujukan untuk menghindari baterai terjadi over discharge karena daya keluaran pada inverter saat on grid akan bekerja maksimum dengan adanya MPPT. Sementara pada saat off grid baterai harus terhubung dengan inverter untuk menstabilkan daya keluaran inverter karena adanya fluktuasi sumber dan beban AC. Penelitian ini bertujuan untuk mengembangkan sistem manajemen baterai yang akan mengatur mekanisme charging dan discharging baterai pada konfigurasi PLTS dengan menggunakan onof grid inverter, sehingga kontinuitas operasi inverter dapat tetap dijaga dalam mensuplai beban.

\section{Metode Penelitian}

\subsection{Konfigurasi Sistem PLTS}

Konfigurasi pembangkit listrik tenaga surya (PLTS) off grid secara umum seperti tampak pada gambar 1a. Panel surya mengkonversi energi radiasi matahari menjadi energi listrik.
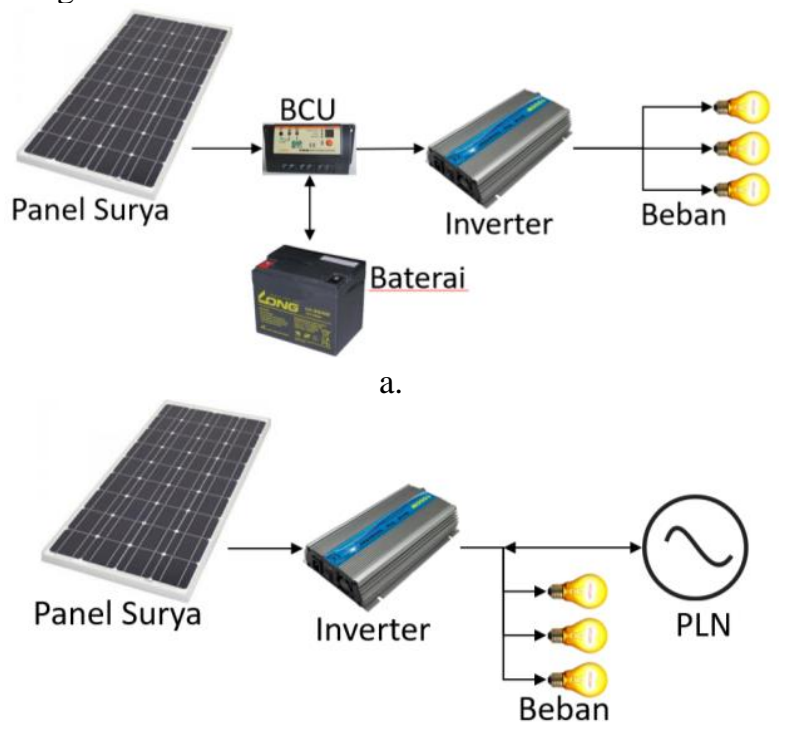

b.

\section{Gambar 1. Konfigurasi PLTS a. On Grid b. Off Grid}

Besarnya daya keluar panel surya adalah : $\mathrm{P}=\mathrm{V} \times \mathrm{I}$ dimana,

- $\mathrm{P}=$ Daya yang dibangkitkan oleh panel surya (watt-peak)

- $\mathrm{V}=$ Tegangan panel surya (volt)

- I = Arus yang mengalir dari panel surya (ampere)

Battery Control Unit (BCU) berfungsi mengatur pengisian dan pembebanan baterai sehingga tidak terjadi over charging dan over discharge.

$\mathrm{I}_{\mathrm{BCU}}>\mathrm{I}_{\text {maks Panel }}$

Dimana,

- $\mathrm{I}_{\mathrm{BCU}}=$ Kapasitas arus BCU

- $\mathrm{I}_{\text {maks panel }}=$ Arus maksimum panel

Pada sistem PLTS baterai digunakan untuk menyimpan kelebihan daya dari panel surya ketika daya beban rendah dan ikut mensuplai beban ketika daya dari panel surya tidak cukup untuk mensuplay beban. Kapasitas muatan baterai dalam satuan Ampere-Jam (AH). Untuk menghitung kapasitas (Ah) dari baterai, dilakukan perhitungan sebagai berikut [4];

Ah yang diperlukan $=E_{k} /(V \times P F)$ dimana,

- $\mathrm{E}_{\mathrm{k}}=$ Kebutuhan energi konsumen

- $\mathrm{V}=$ Tegangan baterai (12 volt)

- $\mathrm{PF}=$ Faktor daya/Power factor $(0,90)$

Depth of Discharge (DOD) diberlakukan pada baterai sesuai dengan ketentuan penggunaan deep cycle battery yang hanya di-discharge sebanyak $50 \%$ dari kapasitas totalnya, maka nilai Ah baterai yang didapat kita kalikan 2. Maka kapasitas baterai adalah ;

Ah Baterai $=2 \times$ Ah yang diperlukan

Inverter seperti dijelaskan pada pendahuluan digunakan untuk merubah daya listrik DC menjadi daya listrik AC. Rangkaian dasar dari inverter untuk dapat merubah daya listrik DC menjadi AC adalah rangkaian $\mathrm{H}$ bridge, seperti tampak pada gambar 2 [5].

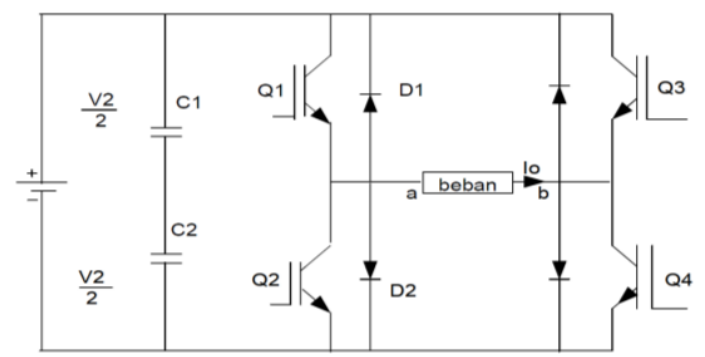

Gambar 2. Topologi H bridge pada inverter off grid

Dengan mengatur mekanisme pensaklaran dari ke empat saklar elektronik dimana kondisi saklat Q1 dan Q4 selalu berlawanan dengan kondisi saklar Q2 dan Q3. Mekanisme pensaklaran ini menyebabkan arus $\left(\mathrm{I}_{\mathrm{o}}\right)$ pada beban akan selalu berganti arah aliran sehingga terjadi pergantian polaritas pada titik tegangan $\mathrm{V}_{\mathrm{ab}}$. Pengaturan 
tegangan inverter yang umum digunakan adalah dengan metode Modulasi Lebar Pulsa (Pulse Width Modulation, PWM).

Pada off grid inverter keluaran inverter hanya terhubung dengan beban. Sementara pada on grid inverter luaran inverter selain terhubung dengan beban juga terhubung dengan jaringan. Salah satu topologi on grid inverter seperti tampak pada gambar 3 [6].

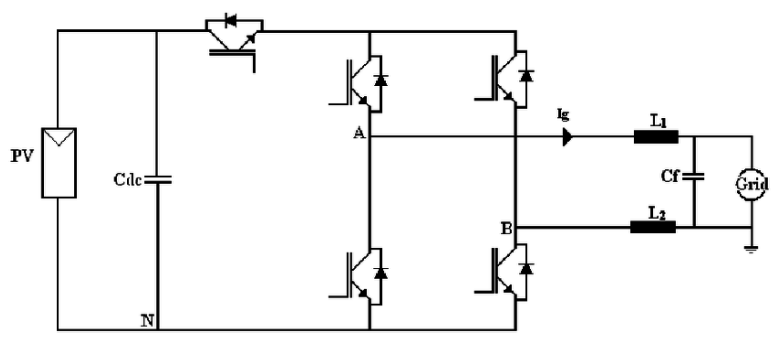

Gambar 3.

Topologi H bridge pada on grid inverter

Pada on grid inverter dilengkai dengan metode MPPT (Maximum Power Point Tracking) sehingga energi dari panel surya dapat dikonversi menjadi energi listrik secara maksimum. Ada bebarapa metode MPPT yang dapat digunakan untuk mendapatkan tegangan kerja yang sesuai dengan titik MPP agar didapatkan daya maksimum antara lain, perturb and observe $(\mathrm{P} \& \mathrm{O})$ dan incremental conductance (INC).

Pada off grid inverter tidak dilengkapi dengan MPPT karena daya yang dihasilkan inverter disesuaikan dengan kebutuhan beban. Kelebihan daya dari panel surya disimpan ke baterai. Secara umum berdasarkan daya yang dihasilkan inverter, maka perbedaan daya keluaran inverter antara on grid dan off grid adalah sebagai berikut,

$$
\begin{gathered}
\mathrm{P}_{\text {on grid inv }} \approx \mathrm{P}_{\text {panel surya }} \\
\mathrm{P}_{\text {off grid inv }}=\mathrm{P}_{\text {beban }}
\end{gathered}
$$

Oleh karena itu pada on grid inverter tidak dihubungkan ke baterai karena jika dihubungkan dengan baterai keseluruhan daya dari baterai akan ikut dikonversi menjadi energi listrik. Hal ini yang perlu diatur pada inverter on/off grid inverter yang ada di Jurusan Teknik Konversi Energi Politeknik Negeri Bandung. Dimana input DC dari panel surya terhubung langsung dengan input DC dari baterai. Pada saat bekerja secara off grid maka kelebihan daya dari solar panel secara otomatis akan mengisi daya ke baterai. Akan tetapi saat bekerja secara on grid, kondisi ini harus dihindari karena dengan MPPT maka energi listrik dari panel surya dan baterai akan dikonversi semaksimal mungkin menjadi daya AC, melebihi daya yang ada di panel surya. Hal ini mendasari perlunya dikembangkan sistem manajemen baterai, yang mengatur interkoneksi baterai ke on-off grid inverter.

\subsection{Penelitian Terkait}

Beberapa penelitian terkait pengembangan sistem manajemen baterai pada pembangkit litrik tenaga surya antara lain :

- Pengembangan sistem manajemen baterai pada sistem PLTS menggunakan inverter dua arah (bidirectional inverter) dilakukan oleh MingChieh Chen (2012) [7]. Hasil pengujian menunjukan sistem yang dikembangkan dapat mengurangi biaya yang hams dikeluar ke grid.

- Sanas Renuka V dan Patil Anupama S (2015) [8] mengembangkan sistem manajemen baterai pada PLTS dengan menambahkan sistem penjejak matahari dan pengaturan pengisian baterai sehingga didapatkan daya pengisian baterai yang lebih efesien dan lebih handal.

- Kivanc Basaran et al (2017) [9] mengembangan sistem manajemen baterai pada sistem PLTS dengan melakukan pengukuran dari berbagai titik dalam sistem sehingga akan didapat sistem transfer energi yang efektif ke baterai, beban, dan jaringan serta peningkatan efisien hingga tingkat $10 \%$.

- Hilman Zarory et al (2014) [10] melakukan perancangan sistem kendali inverter tiga fase untuk mengatur daya aktif dan daya reaktif. Pengendalian arus pada inverter menggunakan metode PI (Proporsional Integral) dan PLL (Phase Locked Loop) yang dipergunakan dalam kondisi sinkron dengan grid. Hasil Simulasi menunjukkan tegangan maupun frekuensi dari mikrogrid dapat dipertahankan dalam kondisi normal.

\subsection{Rancangan penelitian}

Pada penelitian ini akan dikembangkan sistem manajemen baterai yang akan mengatur interkoneksi baterai dengan on/off grid inverter. Dimana pada saat kondisi off grid baterai terhubung langsung ke inverter, sementara saat kondisi on grid baterai harus terlepas dari inverter. Akan tetapi hal yang harus diperhatikan adalah bagaimana mekanisme pengisian baterai, jika dilepaskan dari rangkaian PV dan inverter. Untuk itu rancangan rangkaian sistem manajemen baterai yang dikembangkan seperti tampak pada gambar 4 .

Seperti tampak pada gambar 4 maka saat kondisi off grid, saklar S1 akan menghubungkan BCU ke rangkaian solar panel. Sementara saat kondisi on grid maka BCU akan terhubung dengan modul converter AC/DC. Penggunaan konverter AC/DC agar pengisian baterai tidak hanya dari PV akan tetapi dapat dilakukan dari PLN. Sehingga jika dalam kondisi mendung sementara PLN ada, baterai tetap dapat di charge/diisi daya. Dikondisi yang sama saat PLN mati sistem masih tetap dapat bekerja menghasilkan daya listrik. 


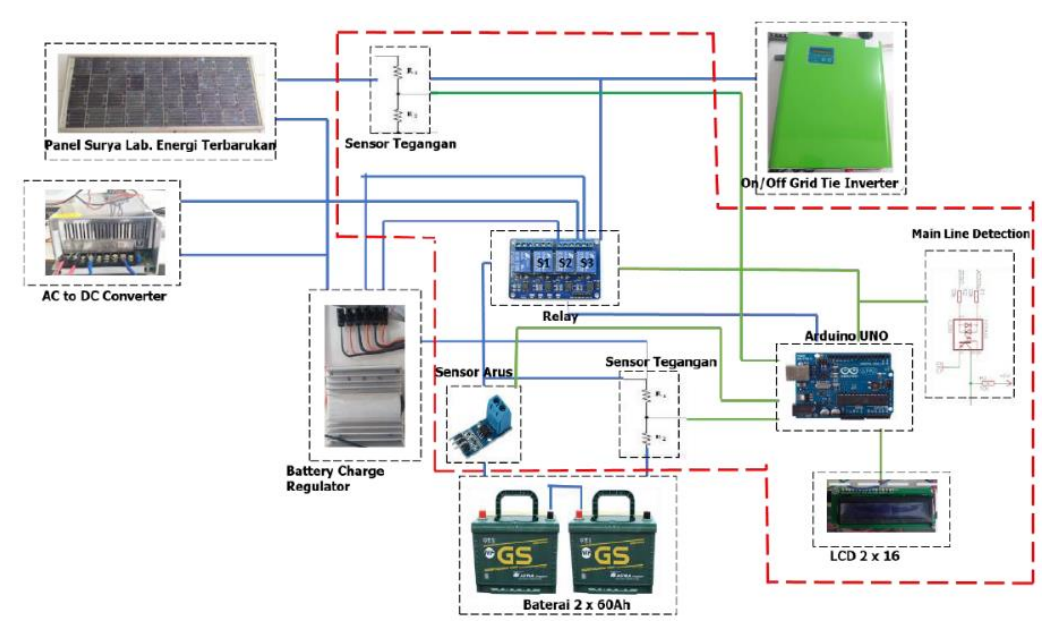

Gambar 4. Rangkaian Sistem Manajemen Baterai

\section{Hasil dan Pembahasan}

Untuk melihat apakah hasil rancangan sistem manajemen baterai yang dikembangkan telah sesuai dengan rancangan maka dilakukan beberapa pengujian dan pengukuran. Pengujian dilakukan mulai pengujian terhadap kinerja inverter baik pada kondisi off grid dan on grid. Pengujian dilakukan dengan melakukan pengukuran daya yang menggambarkan aliran daya dari setiap tahapan rangkaian. Konfigurasi rangkaian pengujian inverter off grid seperti tampak pada gambar 5 . dan data hasil pengukuran seperti tampak pada table 1 .

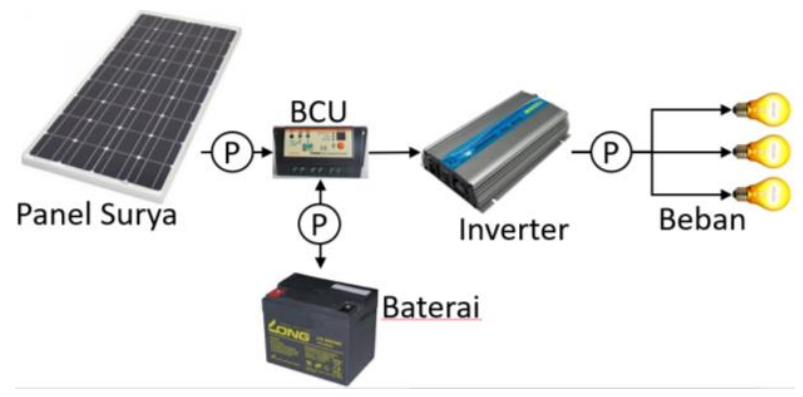

Gambar 5. Rangkaian pengujian Off Grid

Tabel 1. Pengujian Inverter Off Grid

\begin{tabular}{ccrr}
\hline$P(P V)$ & $P(B A T)$ & $P(I N V)$ & \multicolumn{1}{l}{ Radiasi } \\
\hline watt & watt & \multicolumn{1}{l}{ watt } & W/m² \\
(DC) & (DC) & \multicolumn{1}{c}{$($ AC) } & \\
\hline 213,2 & 210,6 & 2,8 & 540 \\
239,2 & 148,98 & 85,9 & 520 \\
275,6 & 80,08 & 179,4 & 535 \\
310,0 & 11,5 & 280,5 & 538 \\
340,8 & $-64,32$ & 367,9 & 551 \\
\hline
\end{tabular}

Pengujian rangkaian on grid inverter dilakukan dengan mengukur daya keluaran pada panel surya, inverter, beban dan daya dari dan ke PLN. Rangkaian pengukuran pengujian on grid seperti tampak pada gambar 6. dan data hasil pengukurannya dapat dilihat pada table 2 .

Pengujian menggunakan panel surya sebanyak 4 buah dengan kapasitas setiap panelnya sebesar 180Wp, sehingga total $720 \mathrm{Wp}$. Inverter yang digunakan adalah BF500 produk dari Foshan Tanfon dengan kapasitas daya keluaran 500W. Baterai yang digunakan 2 x 24V 60Ah. Modul BCU yang digunakan dari landstar dengan tegangan input 12/24VDC dan kapasitas arus maksimum hingga 20A.

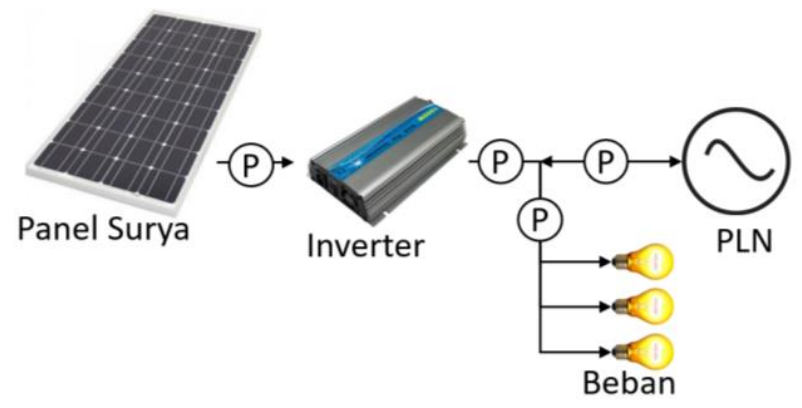

Gambar 6. Rangkaian pengujian On Grid

Tabel 2. Pengujian Inverter On Grid

\begin{tabular}{ccrcr}
\hline$P(P V)$ & $P(I N V)$ & $P($ Load) & $P(P L N)$ & Radiasi \\
\hline watt & watt & watt & watt & W/m $\mathrm{m}^{2}$ \\
(DC) & (AC) & \multicolumn{1}{c}{ (AC) } & \multicolumn{1}{c}{$(\mathrm{AC})$} & \\
\hline 333,7 & 326,3 & 0 & 270,6 & 566 \\
352,5 & 336,4 & 88,24 & 196,4 & 567 \\
352,5 & 329,3 & 181,2 & 120,4 & 566 \\
359,55 & 334,2 & 273,1 & 34,67 & 569 \\
352,5 & 332,1 & 371,4 & -52 & 566 \\
\hline
\end{tabular}


Berdasarkan hasil pengukuran pengujian rangkaian off grid tampak bahwa daya keluaran daya keluaran inverter merupakan total dari daya panel surya (photovoltaic/PV) dan daya baterai. Pengukuran daya pada baterai memberikan nilai daya positif dan negative. Hal ini menunjukkan adanya arah aliran daya. Nilai daya positif menunjukkan adanya aliran daya menuju baterai, sementara daya negative menunjukkan adanya aliran daya keluar dari baterai. Hal ini dikarenakan pada saat daya beban (daya keluaran inverter) rendah, kelebihan daya dari solar panel disimpan ke baterai. Ketika daya beban tinggi dan daya dari panel surya tidak cukup untuk mensuplay beban maka daya dari baterai akan ikut mensuplay beban, seperti tampak pada saat daya beban 367,9 watt daya dari baterai -64,32 watt karena daya dari panel surya hanya 340,8 watt. Dari pengujian ini juga diketahui rata-rata efesiensi dari BCU sebesar 95,1\%.

Hasil pengukuran rangkaian pengujian on grid inverter diperoleh data seperti tampak pada table 2. Berdasarkan erbandingan daya keluaran panel surya terhadap daya keluaran inverter diperoleh efesiensi rata-rata inverter sebesar 94,8\%. Dari hasil pengujian terlihat bahwa daya yang disalurkan PLN memiliki nilai positif dan negative, seperti pada baterai di pengujian sebelumnya. Hal ini menunjukkan bahwa aliran daya dari PLN dapat menuju jaringan atau berasal dari jaringan PLN. Pada empat pengukuran pertama daya dari inverter mampu mensuplai kebutuhan beban dan kelebihan daya disalurkan ke PLN. Akan tetapi saat daya beban maksimum tampak aliran daya dari PLN berubah negative yang berarti arah aliran daya berasal dari PLN. Implementasi rangkaian menggunakan Arduino uno yang dilengkapi dengan layer LED display dan I2C kontroler untuk menampilkan data hasil pengukuran daya keluaran inverter dan daya beban. Pengukuran daya menggunakan modul pengukur arus ACS730. Sementara untuk modul konverter AC/DC dengan tegangan input 220VAC ke 24VDC dan arus maksimum hingga 50A. converter AC/DC digunakan untuk melakukan pengisian baterai dari sumber PLN. Implementasi rangkaian sistem manajemen baterai seperti tampak pada gambar 7 .

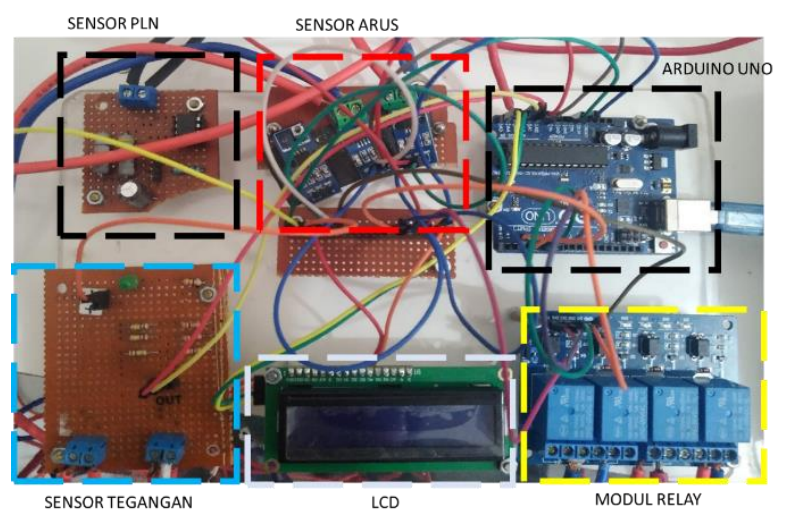

Gambar 7.
Hasil pengujian menunjukkan mekanisme perpindahan dari kondisi off grid ke on grid perlu waktu lebih lama dibandingkan dengan perpindahan on grid ke off grid. Hal ini dikarenakan pada proses transisi dari off grid ke on grid perlu mekanisme sinkronisasi antara inverter dengan jaringan. Hasil pengujian terhadap waktu yang diperlukan untuk transisi dari off grid ke on grid seperti tampak pada table 3 .

Tabel 3. Waktu Transisi Kondisi Off grid-On grid

\begin{tabular}{cc}
\hline Sample & $\begin{array}{c}\text { Waktu } \\
\text { (dtk) }\end{array}$ \\
\hline 1 & 45 \\
2 & 39 \\
3 & 42 \\
4 & 38 \\
5 & 43 \\
\hline Rata-rata & 41,4 \\
\hline
\end{tabular}

Waktu transisi yang diperlukan untuk berpindah dari kondisi off grid ke kondisi on grid rata-rata selama 41,4 detik. Sementara untuk transisi dari kondisi on grid ke kondisi off grid berlangsung seketika sehingga tidak sampai terjadi pemutusan daya.

Tabel 4. Pensaklaran Pengaturan Mode Operasi

\begin{tabular}{|c|c|c|c|c|c|c|c|}
\hline \multirow[t]{2}{*}{ No } & \multicolumn{3}{|c|}{ Input } & \multicolumn{3}{|c|}{ Output } & \multirow[t]{3}{*}{ Ket } \\
\hline & Pin D2 & $\mathrm{Pin} A 3$ & Pin A2 & $\begin{array}{l}\text { Pin } \\
\text { D3 }\end{array}$ & $\begin{array}{l}\text { Pin } \\
\text { D4 }\end{array}$ & $\begin{array}{l}\text { Pin } \\
\text { D5 }\end{array}$ & \\
\hline & $\begin{array}{l}\text { Sensor } \\
\text { PLN }\end{array}$ & $\begin{array}{c}\text { Tegangan } \\
\text { Batt }\end{array}$ & $\begin{array}{c}\text { Tegangan } \\
\text { PV }\end{array}$ & S1 & S2 & S3 & \\
\hline 1 & \multirow{3}{*}{ then } & 0 & 1 & 1 & 1 & 0 & $\begin{array}{l}\text { Mengisi baterai dari } \\
\text { Power Supply }\end{array}$ \\
\hline 2 & & 0 & 0 & 1 & 1 & 0 & $\begin{array}{l}\text { Mengisi baterai dari } \\
\text { Power Supply }\end{array}$ \\
\hline 3 & & 1 & 1 & 0 & 1 & 1 & $\begin{array}{l}\text { Mengirim daya PV } \\
\text { ke Inverter }\end{array}$ \\
\hline 4 & \multirow{4}{*}{0} & 0 & 1 & 0 & 1 & 1 & $\begin{array}{l}\text { Mengisi baterai dari } \\
\text { PV }\end{array}$ \\
\hline 5 & & 0 & 0 & 0 & 0 & 1 & $\begin{array}{l}\text { Tidak melakukan } \\
\text { apapun }\end{array}$ \\
\hline 6 & & 1 & 1 & 0 & 1 & 1 & $\begin{array}{l}\text { Mengirim daya PV } \\
\text { ke Inverter }\end{array}$ \\
\hline 7 & & 1 & 0 & 0 & 1 & 1 & $\begin{array}{l}\text { Mengirim daya } \\
\text { baterai ke Inverter }\end{array}$ \\
\hline
\end{tabular}

Mode operasi dari system manajemen baterai ditentukan oleh konfigurasi dari kondisi saklar S1, S2 dan S3 seperti tampak pada table 4. Kondisi PLN dibaca melalui input digital D2. Kondisi level tegangan PV dan baterai dibaca melalui dua input analog. Hasil pengujian terhadap kinerja sistem manajemen baterai menunjukkan bahwa sistem telah bekerja dengan baik. Khususnya mekanisme Perpindahan interkoneksi baterai dengan rangkaian inverter ke rangkaian pengisian baterai tidak mengganggu kinerja rangkaian PLTS on/off grid telah bekerja sesuai dengan rancangan mode operasi seperti pada table 4 . 


\section{Kesimpulan}

Hasil pengujian dari modul BCU dan inverter yang digunakan menunjukkan efesiensi BCU sebesar 95,1\% dan efesiensi inverter sebesar 94,8\%. Sementara pengujian terhadap kinerja sistem manajemen baterai menunjukkan bahwa sistem telah bekerja dengan baik. Waktu transisi yang diperlukan untuk berpindah dari kondisi off grid ke kondisi on grid selama 41,4 detik. Sementara waktu yang diperlukan untuk transisi dari kondisi on grid ke off grid berlangsung seketika, tanpa terjadi pemutusan daya. Perpindahan interkoneksi baterai dengan rangkaian inverter ke rangkaian pengisian baterai tidak mengganggu kinerja rangkaian PLTS on/off grid.

\section{Daftar Acuan}

[1] Zhilei Yao, Lan Xiao, dan Yangguang Yan, "Seamless Transfer of Single-Phase Grid-Interactive Inverters Between Grid-Connected and Stand-Alone Modes", IEEE Transactions On Power Electronics, VOL. 25, NO. 6, JUNE 2010, page 1597-1603

[2] Hartono Budi Santoso and Budiyanto, Microgrid Development Using A Grid Tie Inverter, Makara Seri Teknologi, 2013, 17(3): 121-127

[3] Rudy Setiabudy, Hartono BS dan Budiyanto, The Characteristics Analysis Of On/Off Grid Tie Inverter and The Implementation on Microgrid, TELKOMNIKA, Vol.11, No.3, September 2013, pp. 441 450

[4] Ruskardi, Kajian Teknis dan Analisis Ekonomis PLTS Off-grid Solar System sebagai Sumber Energi
Alternatif (Studi Kasus : Dusun Sedayu Desa Pulau Limbung Kecamatan Sungai Raya Kabupaten Kubu Raya), Jurnal ELKHA Vol.7, No 1,Maret 2015

[5] Hazlif Nazif, Muh. Imran Hamid, Pemodelan Dan Simulasi Pv-Inverter Terintegrasi Ke Grid Dengan Kontrol Arus Ramp Comparison Of Current Control, Jurusan Teknik Elektro, Fakultas Teknik, Universitas AndalasJurnal Nasional Teknik Elektro, Vol: 4, No. 2, September 2015

[6] Tarak Salmi, Mounir Bouzguenda, Adel Gastli, Ahmed Masmoudi, Transformerless microinverter for photovoltaic systems, International Journal Of Energy And Environment, Volume 3, Issue 4, 2012 pp.639-650 [7] Ming-Chieh Chen, An Intelligent Lead Acid Battery Management System for Solar and Off-Peak Energy Storage, Master Thesis, Electrical Engineering, The University of Toledo, 2012

[8] Sanas Renuka V, Patil Anupama S, Development of Battery Management System for PV Generation, International Journal of Advanced Research in Electrical, Electronics and Instrumentation Engineering, Vol. 4, Issue 6, June 2015, pp: 5229-5233 [9] Basaran Kivanç, Çetin Numan dan Borekci Selim, Energy Management for on-grid and off-grid Wind/PV and Battery Hybrid Systems, IET Renewable Power Generation, vol 11 pp : 642-649

[10] Hilman Zarory, F. Danang Wijaya, dan Bambang Sutopo, Kendali Penyimpan Energi Listrik untuk Aplikasi Mikrogrid, JNTETI, Vol. 3, No. 2, Mei 2014, pp: 146-151 